\title{
Signs, symptoms, and treatment patterns across serial ambulatory cardiology visits in patients with heart failure: insights from the NCDR PINNACLE ${ }^{\circledR}$ registry
}

Larry A. Allen ${ }^{1 *} \mathbb{D}$, Fengming Tang ${ }^{2}$, Philip Jones ${ }^{2}$, Tracie Breeding ${ }^{2}$, Angelo Ponirakis ${ }^{3}$ and Stuart J. Turner ${ }^{4}$

\begin{abstract}
Background: Due to a relative lack of outpatient heart failure (HF) clinical registries, we aimed to describe symptoms, signs, and medication treatment among ambulatory patients with heart failure (HF) over time.

Methods: Using health records from 234 PINNACLE (Practice Innovation and Clinical Excellence) U.S. cardiology practices (2008-2014), serial visits for patients with HF were characterized. Symptoms, signs, and HF medications (angiotensin-converting enzyme inhibitors [ACEI], angiotensin receptor blockers [ARB], beta blockers [BB], and diuretics) were compared between visits.

Results: Among 763,331 patients with HF, 550,581 had $\geq 2$ clinic visits $<1$ year apart, with 2,998,444 visit pairs. In the 12 months following an index visit, patients had a mean of $2.5 \pm 2.3$ additional visits. Recorded index visit symptoms ranged from dyspnea (53.6\%) to orthopnea (23.1\%); signs ranged from peripheral edema $(52.2 \%)$ to hepatomegaly (0.6\%). Of those with ejection fraction < 40\%, ACEI was prescribed in $58.6 \%$, ARB in $18.5 \%$, BB in $85.2 \%$, and diuretics in 70.0\%. Between-visit recorded changes were infrequent: dyspnea appeared in 3.8\%, resolved in 2.7\%; NYHA class increased in 2.9\%, decreased in 2.9\%; number of signs increased in $6.0 \%$, decreased in $5.1 \%$; ACEI/ARB or BB added in 6.4\%, removed in 6.2\%; diuretic added in 3.7\%, removed in 3.8\%. Changes in recorded symptoms were rarely associated with initiation or discontinuation in HF medication classes.

Conclusions: Ambulatory HF care in U.S. cardiology practices seldom recorded changes in symptoms, signs, and medication class. Although templated medical records and absence of medication dosing likely underestimated the degree to which clinical changes occur over serial visits for HF, these PINNACLE data suggest opportunities for greater symptom-based and therapy-focused visits.
\end{abstract}

Keywords: Ambulatory care, Drug therapy, Heart failure, Registries, Dyspnea

\section{Background}

The nearly 6 million Americans with heart failure (HF) account for more than 12 million physician office visits each year [1-4]. From patient and clinician perspectives, these medical encounters provide an opportunity to improve the medical management of HF, which in turn has the potential to relieve the symptoms of $\mathrm{HF}$, improve health-related

\footnotetext{
* Correspondence: larry.allen@ucdenver.edu

${ }^{1}$ Division of Cardiology, University of Colorado School of Medicine, Anschutz Medical Campus, 12631 E. 17th Avenue, Academic Office 1, \#7019, Mail Stop B130, Aurora, CO 80045, USA

Full list of author information is available at the end of the article
}

quality of life, reduce hospitalizations, and prolong survival [5-9]. Current clinical practice guidelines recommend the serial optimization of HF medication therapies, involving dose titration and monitoring to achieve maximum symptom relief and medication tolerability $[5,7,8,10]$.

A number of patient registries have been established to characterize patients with HF and the care received in routine clinical practice. However, due to a variety of logistical issues, they have been primarily limited to inhospital care, administrative billing data, or a small number of sites, and thus have been unable to provide a comprehensive look at ambulatory HF care across the

(c) The Author(s). 2018 Open Access This article is distributed under the terms of the Creative Commons Attribution 4.0 International License (http://creativecommons.org/licenses/by/4.0/), which permits unrestricted use, distribution, and reproduction in any medium, provided you give appropriate credit to the original author(s) and the source, provide a link to the Creative Commons license, and indicate if changes were made. The Creative Commons Public Domain Dedication waiver (http://creativecommons.org/publicdomain/zero/1.0/) applies to the data made available in this article, unless otherwise stated. 
U.S. [11-14]. The American College of Cardiology's National Cardiovascular Data Registry's (NCDR ${ }^{\circ}$ ) PINNACLE (Practice Innovation and Clinical Excellence) Registry ${ }^{\circ}$ is now the largest contemporary clinical database of ambulatory cardiology care, which includes detailed information on symptoms, signs, medication prescribing, procedures, and outcomes from patients diagnosed with a variety of cardiovascular $(\mathrm{CV})$ conditions [15-19]. Using this emerging real-world ambulatory view provided by the PINNACLE Registry, we sought to characterize changes in recorded symptoms, physical signs, and prescribing of medication classes across serial ambulatory cardiology visits for patients with HF.

\section{Methods}

\section{Study design}

PINNACLE is the first U.S. national, prospective, office-based, quality improvement registry for CV ambulatory care in the U.S. Participation is voluntary, and data are routinely collected and submitted to the American College of Cardiology's NCDR from participating practices using paper-based chart abstraction or a mapping algorithm from electronic health records [18]. The current study was a cross-sectional analysis of patients $\geq 18$ years of age enrolled in the PINNACLE Registry with a diagnosis code for HF between May 1, 2008, and December 30, 2014. Included patients had at least 1 pair of ambulatory visits less than 1 year apart. Diagnosis of HF was defined using PINNACLE Registry criteria of unusual dyspnea on light exertion, recurrent dyspnea occurring in the supine position, fluid retention, and low cardiac output secondary to cardiac dysfunction; via the description of rales, jugular venous distension, or pulmonary edema constituted HF; or as a previous hospital admission with primary diagnosis of $\operatorname{HF}[20,21]$. The first visit in the first pair of ambulatory visits was defined as the index visit. Baseline characteristics were assessed at the time of the first visit (index visit). To assess changes in symptoms, signs, and treatment, all subsequent visits following the index visit were compared against the visit immediately prior if the 2 visits were less than 1 year apart. Data were extracted directly from the practices' electronic health record or via a paper-based reporting form. Data collection was standardized using established definitions, uniform data entry and transmission, and quality checks. In addition, rigorous back-end data quality checks were performed on the extracted data. Any data not meeting predefined quality thresholds were quarantined from analyses and flagged for manual review and follow-up with individual practices [18]. Missing data for any visit were handled using a last observation carried forward approach, where available.

\section{Study outcomes}

The primary outcomes of interest were the associations between changes in the incidence of the signs and symptoms of HF and changes in medications at a class level. The signs and symptoms of HF assessed included changes in New York Heart Association (NYHA) functional class, the presence of dyspnea and orthopnea, as well as changes in the number of physical signs of HF present, including rales, ascites, peripheral edema, hepatomegaly, third heart sound ( $S_{3}$ gallop), fourth heart sound ( $\mathrm{S}_{4}$ gallop), and jugular vein distention. Medications were classified as angiotensin-converting enzyme inhibitors (ACEI), angiotensin receptor blockers (ARB), beta blockers (BB), and diuretics.

Due to limitations in the granularity of medication capture, loop diuretics, thiazides, diuretics, and mineralocorticoid receptor antagonists were grouped as a single diuretics category during PINNACLE data collection. Therefore, MRA (spironolactone and eplerenone) cannot be distinguished from other diuretics, including commonly used loop diuretics (e.g. furosemide). Thus, "diuretics" represents a heterogeneous class in this analysis. At each visit, patients were assessed for presence or absence of a prescription for each of the 3 classes: 1 ) $\mathrm{ACEI} / \mathrm{ARB}$, 2) $\mathrm{BB}$, and 3) diuretics. Medication treatment change between visits was classified into 1 of 3 groups: 'increase' (no to yes), 'decrease' (yes to no), or 'no change' in the number of HF medication classes prescribed. Currently, PINNACLE data capture does not allow for an analysis of HF medication dosing.

\section{Data analyses}

Demographics and clinical characteristics were represented as means and standard deviations (SD) for continuous variables and frequencies and percentages for categorical variables. The association between treatment patterns and change in HF symptoms and physical assessments was described using percentages of treatment 'increase,' 'decrease', and 'no change' in HF symptoms and physical assessment categories. Rate ratios for treatment increase and treatment decrease were also calculated for patients with HF symptoms and physical assessment increase and decrease relative to those with no change. The frequency of HF treatment modifications in 1 year of follow-up after index, number of subsequent visits after index per patient, and time between 2 consecutive eligible visits using mean, interquartile range, and SD were also described. All analyses were then repeated and stratified by age group ( $<65$ and $\geq 65$ years), and within the subset with reduced left-ventricular ejection fraction $(\mathrm{LVEF}<40 \%)$.

A number of key variables in PINNACLE had nontrivial missing rates. To assess for potential bias, the demographics and clinical characteristics of the visits 
included versus those of the visits excluded due to missing data were described using means (SD) for continuous variables and frequencies (percentages) for categorical variables. In the sensitivity analysis to evaluate the impact of potential bias due to missing values, we repeated the primary analysis using inverse probability weighting, which assigned higher weights to visits that were similar to those with missing values. The probability weights were calculated from a logistic regression model on the basis of patient demographics and clinical characteristics. Data collection was standardized through the use of standard definitions, uniform data entry and transmission requirements, and data quality checks.

\section{Results}

Frequency of cardiology visits among patients with HF A total of 4,713,004 patients were identified in the PINNACLE Registry from 234 practices from May 1, 2008 to December 30, 2014. From 763,331 patients who had a documented diagnosis of HF, 550,581 patients (72.1\%) from 224 practices had at least 2 ambulatory visits less than 1 year apart. The total number of qualified visit pairs was 2,998,444. The mean length of follow-up per patient was $1.9 \pm 1.6$ years. In the 12 months following an index visit, patients had a mean of $2.5 \pm 2.3$ additional visits.

\section{Findings at index visit}

The baseline demographics and clinical characteristics of the study population are presented in Table 1 . The mean (SD) age of the population was 69.7 (13.4) years, 45.1\% were women, and $87.4 \%$ were white. LVEF was available in $52.2 \%$ of the patients; $26.1 \%$ of patients with an LVEF measure had a LVEF $<40 \%$ at the index visit. The most common comorbidities were hypertension (82.2\%) followed by dyslipidemia (65.0\%) and coronary artery disease (60.9\%).

Symptoms of dyspnea and orthopnea were reported in $53.6 \%$ and $23.1 \%$ of patients at the index visit, respectively. Patients were predominantly in NYHA functional class $1(59.7 \%)$ at the index visit, with an additional $29.3 \%$ of patients in class 2 . The most frequently reported physical sign of HF was peripheral edema (52.2\%), followed by $\mathrm{S}_{4}$ gallop (12.3\%). At the index visit, an ACEI/ $\mathrm{ARB}$ or $\mathrm{BB}$ were not prescribed for $17.5 \%$ of patients; $68.8 \%$ were prescribed $\mathrm{BB}, 43.6 \%$ were prescribed $\mathrm{ACEI}$, and $20.7 \%$ were prescribed ARB; $47.3 \%$ of patients were on a combination of an ACEI/ARB plus a BB and 35.1\% were on either an ACEI/ARB or a BB. Diuretics were prescribed for $56.4 \%$ of patients.

A number of variables in PINNACLE had a significant proportion of missing data across visits: NYHA (66.1\% missing), dyspnea (17.1\% missing), orthopnea (11.4\% missing), and any of the 7 physical signs, including rales, peripheral edema, $\mathrm{S}_{3}$ gallop, $\mathrm{S}_{4}$ gallop, ascites, hepatomegaly, and jugular vein distension (35.0\% missing). However, the results of sensitivity analyses were consistent with the primary analyses, highlighting that the missing data in the PINNACLE Registry were likely missing primarily at random (data not shown).

\section{Changes in symptoms, signs, and medication prescribing}

Changes in HF symptoms and signs (increase or decrease) at clinic visits were infrequently reported (percent of patients): dyspnea appeared in $3.8 \%$ and resolved in $2.7 \%$; NYHA class increased in $2.9 \%$ and decreased in $2.9 \%$; and number of signs increased in $6.0 \%$ and decreased in $5.1 \%$. Changes in HF medication classes were also infrequent: an ACEI/ARB or BB was added in $6.4 \%$ and removed in 6.2\%; a diuretic was added in $3.7 \%$ and removed in $3.8 \%$ of patients.

In the 12 months following an index visit, patients had a mean of $0.3 \pm 0.63 \mathrm{HF}$ drug class modifications (i.e., drug class addition or removal). Changes in symptoms and signs of HF were infrequently associated with a change in $\mathrm{HF}$ medications (Table 2). For example, an ACEI/ARB or BB was added in $15.0 \%$ of visits where dyspnea appeared and removed in $18.7 \%$ of visits where dyspnea resolved; a diuretic was added in $9.1 \%$ of visits where dyspnea appeared and removed in $10.3 \%$ of visits where dyspnea resolved. Changes in medication treatment patterns associated with changes in other signs and symptoms followed a similar pattern (Table 2). Rate ratios tended to follow a pattern that indicated an increased frequency of the addition of a medication class associated with symptom or sign worsening and a decreased frequency of the addition of a medication class associated with symptom or sign improvement, compared with no change in symptoms or signs (Table 2).

\section{Patients with LVEF $<40 \%$}

For the 75,107 patients with an LVEF $<40 \%$, baseline demographic and clinical characteristics were similar to the overall study population; however, there was a greater percentage of men in the LVEF $<40 \%$ subgroup $(69.1 \%$ vs $54.9 \%)$. Patients with $\operatorname{LVEF}<40 \%$ and available data were mainly NYHA functional class $2(46.5 \%)$ or 1 (29.0\%) and more likely to be prescribed HF medications: BB (85.2\%), a diuretic (70.0\%), an ACEI (58.6\%), or an ARB (18.5\%) (Table 1).

Consistent with the results of the overall study population, patients with LVEF $<40 \%$ also rarely reported changes in symptoms and signs of HF or in HF medication class, with the majority of patients reporting no changes after the index date (Table 3 ). The rate ratios for treatment increase or decrease associated with changes in HF symptoms and signs followed a similar pattern as that observed for the overall population (Table 3). 
Table 1 Baseline patient demographics and clinical characteristics

\begin{tabular}{|c|c|c|c|c|}
\hline & $\begin{array}{l}\text { OVERALL STUDY POPULATION } \\
(n=550,581)\end{array}$ & $\begin{array}{l}\text { Patients with } \\
\text { Data Available }\end{array}$ & $\begin{array}{l}\text { Patients with LVEF }<40 \% \\
(n=75,107)\end{array}$ & $\begin{array}{l}\text { Patients > 65 Years of Age } \\
(n=374,580)\end{array}$ \\
\hline Age, yrs & $69.7 \pm 13.4$ & $100 \%$ & $68.6 \pm 13.1$ & $77.0 \pm 7.6$ \\
\hline Sex & & $99.7 \%$ & & \\
\hline Men & $54.9 \%$ & & $69.1 \%$ & $53.2 \%$ \\
\hline Race & & $42.5 \%$ & & \\
\hline White & $87.4 \%$ & & $86.3 \%$ & $91.1 \%$ \\
\hline Black & $10.1 \%$ & & $12.0 \%$ & $6.7 \%$ \\
\hline Other & $2.5 \%$ & & $1.7 \%$ & $2.2 \%$ \\
\hline \multicolumn{5}{|l|}{ Ethnicity } \\
\hline Hispanic & $1.9 \%$ & $93.7 \%$ & $2.2 \%$ & $1.8 \%$ \\
\hline \multicolumn{5}{|l|}{ Comorbidities } \\
\hline Hypertension & $82.2 \%$ & $92.5 \%$ & $77.1 \%$ & $84.7 \%$ \\
\hline Dyslipidemia & $65.0 \%$ & $86.9 \%$ & $68.6 \%$ & $68.4 \%$ \\
\hline Coronary artery disease & $60.9 \%$ & $93.9 \%$ & $70.7 \%$ & $65.3 \%$ \\
\hline Atrial fibrillation/flutter & $34.2 \%$ & $92.0 \%$ & $35.8 \%$ & $41.2 \%$ \\
\hline Type 2 diabetes & $28.1 \%$ & $94.4 \%$ & $30.7 \%$ & $28.2 \%$ \\
\hline Previous myocardial infarction & $21.7 \%$ & $86.8 \%$ & $31.4 \%$ & $22.4 \%$ \\
\hline Stable angina & $11.5 \%$ & $86.7 \%$ & $11.2 \%$ & $12.5 \%$ \\
\hline Peripheral arterial disease & $10.8 \%$ & $87.9 \%$ & $11.4 \%$ & $12.4 \%$ \\
\hline Stroke/transient ischemic attack & $6.1 \%$ & $77.6 \%$ & $5.8 \%$ & $7.1 \%$ \\
\hline Ischemic stroke & $2.5 \%$ & $36.5 \%$ & $2.5 \%$ & $2.9 \%$ \\
\hline Unstable angina & $2.4 \%$ & $96.1 \%$ & $2.4 \%$ & $2.5 \%$ \\
\hline NYHA functional class & & $32.0 \%$ & & \\
\hline 1 & $59.7 \%$ & & $29.0 \%$ & $54.0 \%$ \\
\hline 2 & $29.3 \%$ & & $46.5 \%$ & $33.1 \%$ \\
\hline 3 & $10.0 \%$ & & $22.3 \%$ & $11.8 \%$ \\
\hline 4 & $1.0 \%$ & & $2.3 \%$ & $1.1 \%$ \\
\hline \multicolumn{5}{|l|}{ Symptoms } \\
\hline Dyspnea & $53.6 \%$ & $85.7 \%$ & $57.4 \%$ & $55.2 \%$ \\
\hline Orthopnea & $23.1 \%$ & $88.7 \%$ & $24.5 \%$ & $23.3 \%$ \\
\hline Systolic BP, mm Hg & $127.7 \pm 19.5$ & $93.0 \%$ & $121.8 \pm 19.0$ & $128.1 \pm 19.4$ \\
\hline Diastolic BP, mm Hg & $73.2 \pm 11.6$ & $93.0 \%$ & $71.7 \pm 11.8$ & $71.3 \pm 10.9$ \\
\hline Heart rate, bpm & $72.9 \pm 13.6$ & $86.6 \%$ & $74.1 \pm 13.6$ & $72.0 \pm 13.2$ \\
\hline \multicolumn{5}{|l|}{ Physical signs } \\
\hline Rales & $4.9 \%$ & $86.2 \%$ & $6.2 \%$ & $5.7 \%$ \\
\hline Ascites & $0.8 \%$ & $92.9 \%$ & $1.1 \%$ & $0.8 \%$ \\
\hline Peripheral edema & $52.2 \%$ & $77.2 \%$ & $54.2 \%$ & $53.4 \%$ \\
\hline Hepatomegaly & $0.6 \%$ & $96.1 \%$ & $1.0 \%$ & $0.6 \%$ \\
\hline $\mathrm{S}_{3}$ gallop & $6.9 \%$ & $91.8 \%$ & $8.6 \%$ & $7.3 \%$ \\
\hline $\mathrm{S}_{4}$ gallop & $12.3 \%$ & $89.1 \%$ & $11.6 \%$ & $12.8 \%$ \\
\hline$J V D$ & $6.8 \%$ & $91.8 \%$ & $8.4 \%$ & $7.2 \%$ \\
\hline $\mathrm{BMl}, \mathrm{kg} / \mathrm{m}^{2}$ & $30.8 \pm 9.6$ & $74.3 \%$ & $29.9 \pm 9.0$ & $29.6 \pm 9.0$ \\
\hline Tobacco use & & $52.1 \%$ & & \\
\hline Never & $40.1 \%$ & & $34.3 \%$ & $40.0 \%$ \\
\hline
\end{tabular}


Table 1 Baseline patient demographics and clinical characteristics (Continued)

\begin{tabular}{|c|c|c|c|c|}
\hline & $\begin{array}{l}\text { OVERALL STUDY POPULATION } \\
(n=550,581)\end{array}$ & $\begin{array}{l}\text { Patients with } \\
\text { Data Available }\end{array}$ & $\begin{array}{l}\text { Patients with LVEF }<40 \% \\
(n=75,107)\end{array}$ & $\begin{array}{l}\text { Patients }>65 \text { Years of Age } \\
(n=374,580)\end{array}$ \\
\hline Current & $14.4 \%$ & & $17.0 \%$ & $11.2 \%$ \\
\hline Quit within 12 months & $3.3 \%$ & & $4.0 \%$ & $3.2 \%$ \\
\hline Quit more than 12 months ago & $42.1 \%$ & & $44.7 \%$ & $45.7 \%$ \\
\hline LVEF & & $52.2 \%$ & & \\
\hline$\geq 50 \%$ & $58.3 \%$ & & & $60.5 \%$ \\
\hline $40-49 \%$ & $15.6 \%$ & & & $15.5 \%$ \\
\hline$<40 \%$ & $26.1 \%$ & & $100 \%$ & $24.0 \%$ \\
\hline Treatment & & $100 \%$ & & \\
\hline ACEl & $43.6 \%$ & & $58.6 \%$ & $42.3 \%$ \\
\hline ARB & $20.7 \%$ & & $18.5 \%$ & $22.1 \%$ \\
\hline BB & $68.8 \%$ & & $85.2 \%$ & $70.0 \%$ \\
\hline Diuretic & $56.4 \%$ & & $70.0 \%$ & $60.0 \%$ \\
\hline \multicolumn{5}{|l|}{ Medical procedures/ devices } \\
\hline $\mathrm{PCl}$ & $1.0 \%$ & $70.1 \%$ & $1.3 \%$ & $1.0 \%$ \\
\hline Pacemaker & $9.2 \%$ & $35.2 \%$ & $24.1 \%$ & $10.1 \%$ \\
\hline CRT-D & $9.5 \%$ & $34.9 \%$ & $24.4 \%$ & $10.4 \%$ \\
\hline ICD & $11.1 \%$ & $34.8 \%$ & $29.7 \%$ & $11.5 \%$ \\
\hline
\end{tabular}

$A C E l$ angiotensin-converting enzyme inhibitor, $A R B$ angiotensin receptor blocker, $B B$ beta blocker, $B M I$ body mass index, $B P$ blood pressure, $b p m$ beats per minute, $C R T$ - $D$ cardiac resynchronization therapy plus defibrillator, ICD implantable cardioverter defibrillators, $J V D$ jugular vein distention, $L V E F$ left ventricular ejection fraction, $m m$ Hg millimeters of mercury, NYHA New York Heart Association, $P C l$ percutaneous coronary intervention, $S_{3}$ third heart sound, $S_{4}$ fourth heart sound, yrs. years

\section{Patients $\leq 65$ and $>65$ years of age}

For the 374,580 patients $>65$ years of age, with the exception of age (mean [SD]: $77.0 \pm 7.6$ years), baseline demographic and clinical characteristics were analogous to the overall study population. Changes in the prescribing of HF medication were similarly rarely observed irrespective of age. For patients $\leq 65$ and $>65$ years of age at index, the rate ratios for treatment increase or decrease associated with changes in HF symptoms and signs followed a similar pattern as that observed for the overall population (Tables 4 and 5 ).

\section{Discussion}

For patients with HF, the frequency of cardiology clinic visits, changes in symptoms and signs between visits, changes in HF medication class prescribing patterns at visits, and the relationship between them has not been previously described across the U.S. ambulatory cardiology setting. The current study found that the majority of patients with HF had 2 or more cardiology clinic visits in a year. Health records from these visits rarely recorded changes in dyspnea, orthopnea, NYHA functional class, or physical signs between visits. Further, HF medication class modifications were infrequent. Although predictable associations between changes in symptoms/signs and drug therapy were observed, particularly the addition of medication with increases in dyspnea and vice versa, the absolute rate of initiation and discontinuation of drug classes was small. This apparent lack of major HF treatment modification during ambulatory visits (recognizing the limitations of health record data generally and the absence of medication dosing here specifically) is a finding that warrants further investigation, either as a potential opportunity to more proactively optimize HF medication prescribing at cardiology visits (particularly in the HF population with reduced LVEF) or as an opportunity to reduce some routine follow-up visits in the absence of clinical change.

The vast majority of real-world HF data have been collected from inpatient settings, including the hospitalbased registries such as the Organized Program to Initiate Lifesaving Treatment in Hospitalized Patients with Heart Failure (OPTIMIZE-HF) [11] and Get With The Guidelines ${ }^{\oplus}$-Heart Failure (GWTG-HF) [14]. Ambulatory data have primarily been collected from randomized controlled trials, with limitations in external validity due to narrow inclusion criteria and algorithms for medication management $[18,22,23]$. A real-world ambulatory evaluation of care for patients with HF was provided through Improve the Use of Evidence-Based Heart Failure Therapies in the Outpatient Setting (IMPROVE-HF) $[12,19,24]$, but those data represented a narrow cohort of participating centers and are becoming increasingly dated. PINNACLE represents the largest ambulatory data available for Americans diagnosed with a variety of $\mathrm{CV}$ conditions (coronary artery disease, hypertension, 


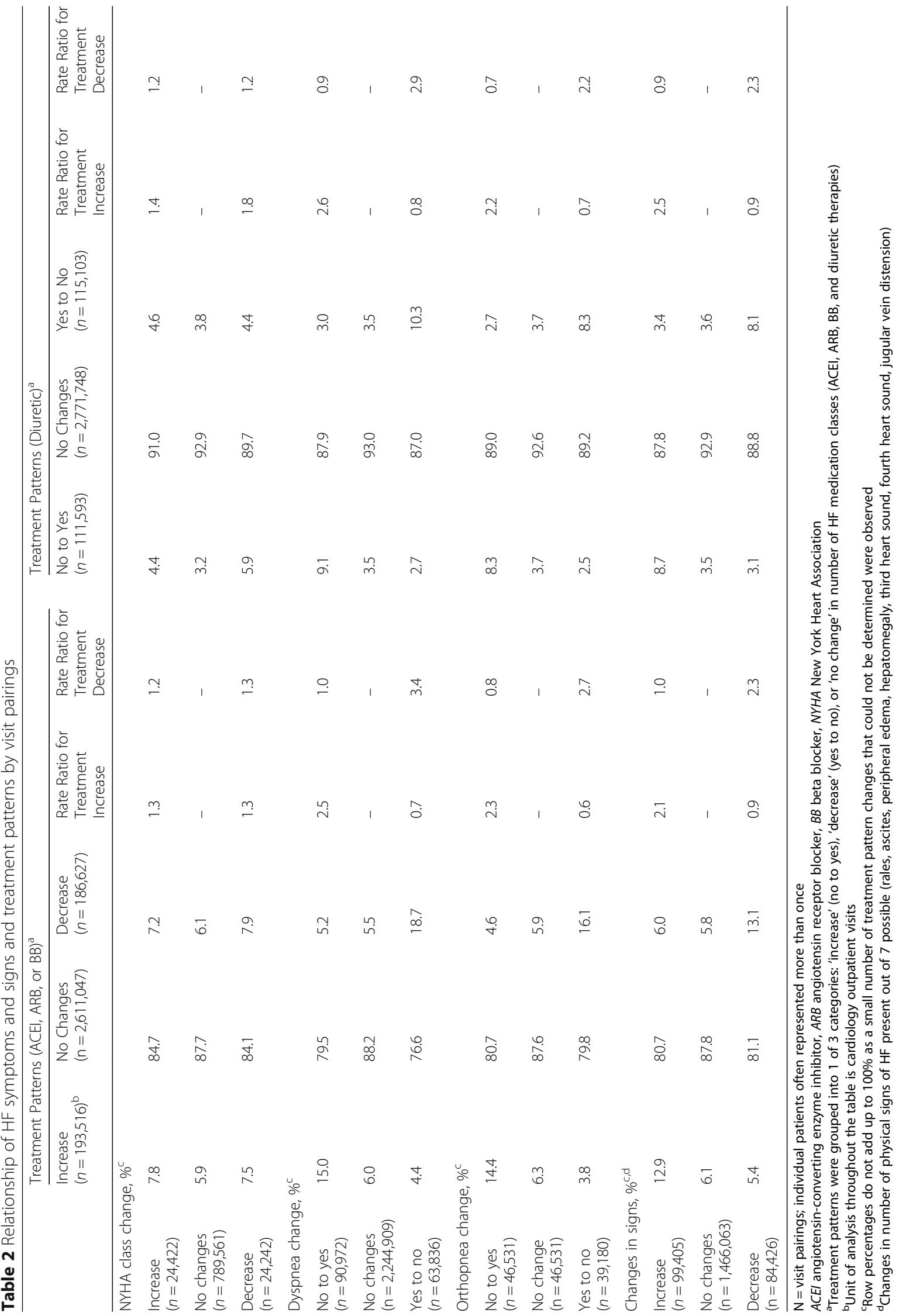


Allen et al. BMC Cardiovascular Disorders (2018) 18:80

Page 7 of 11

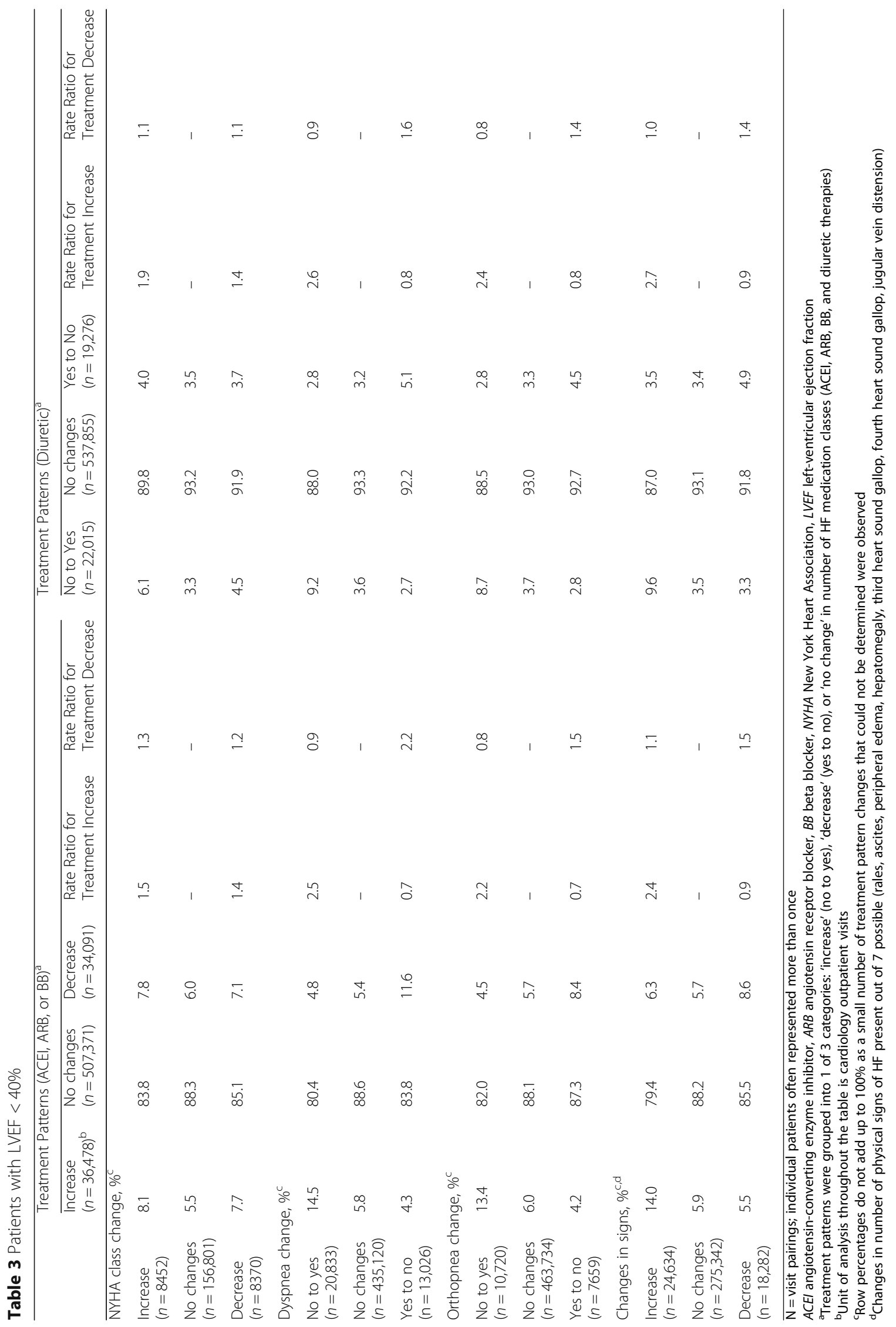




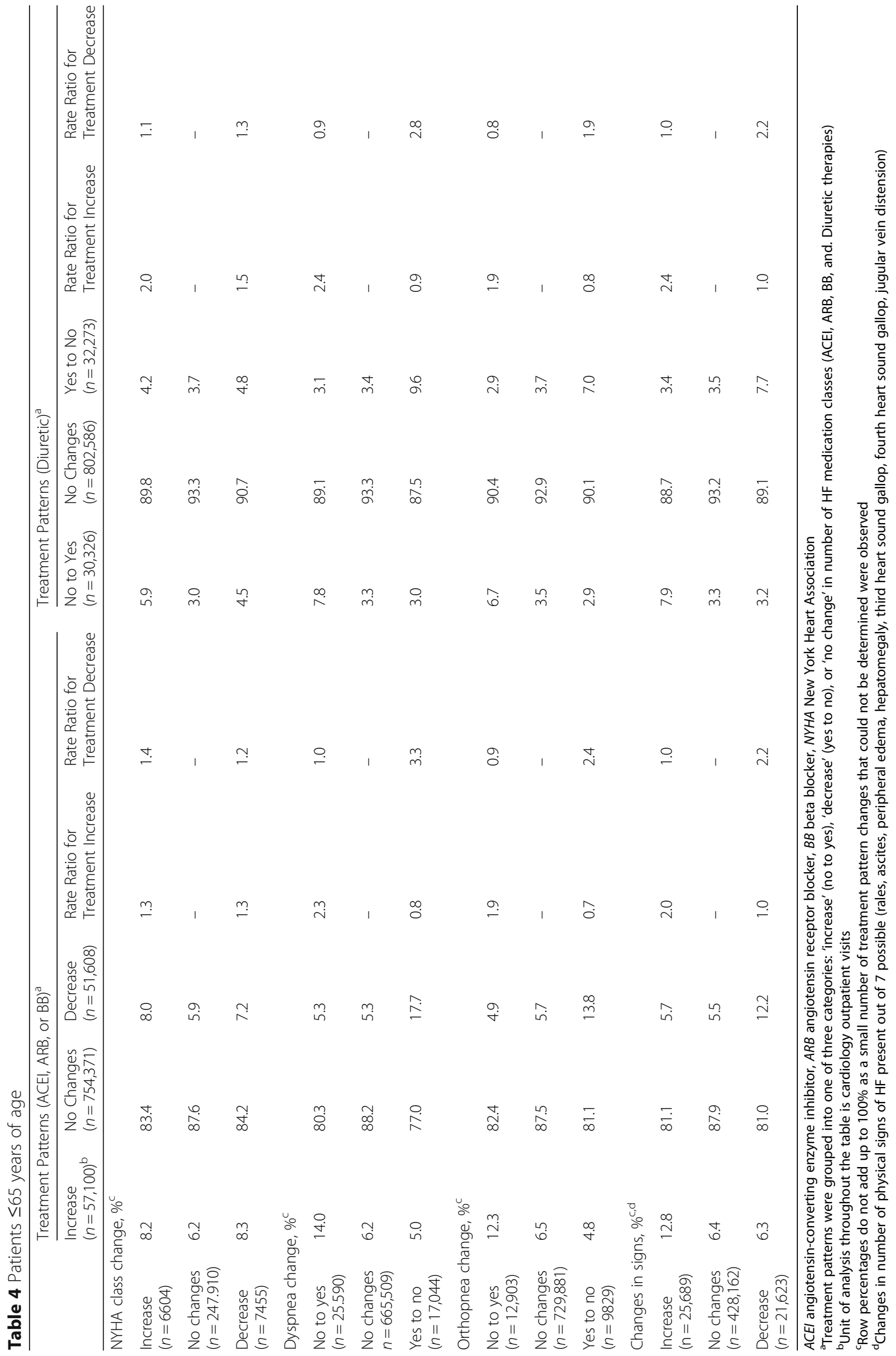


Allen et al. BMC Cardiovascular Disorders (2018) 18:80

Page 9 of 11

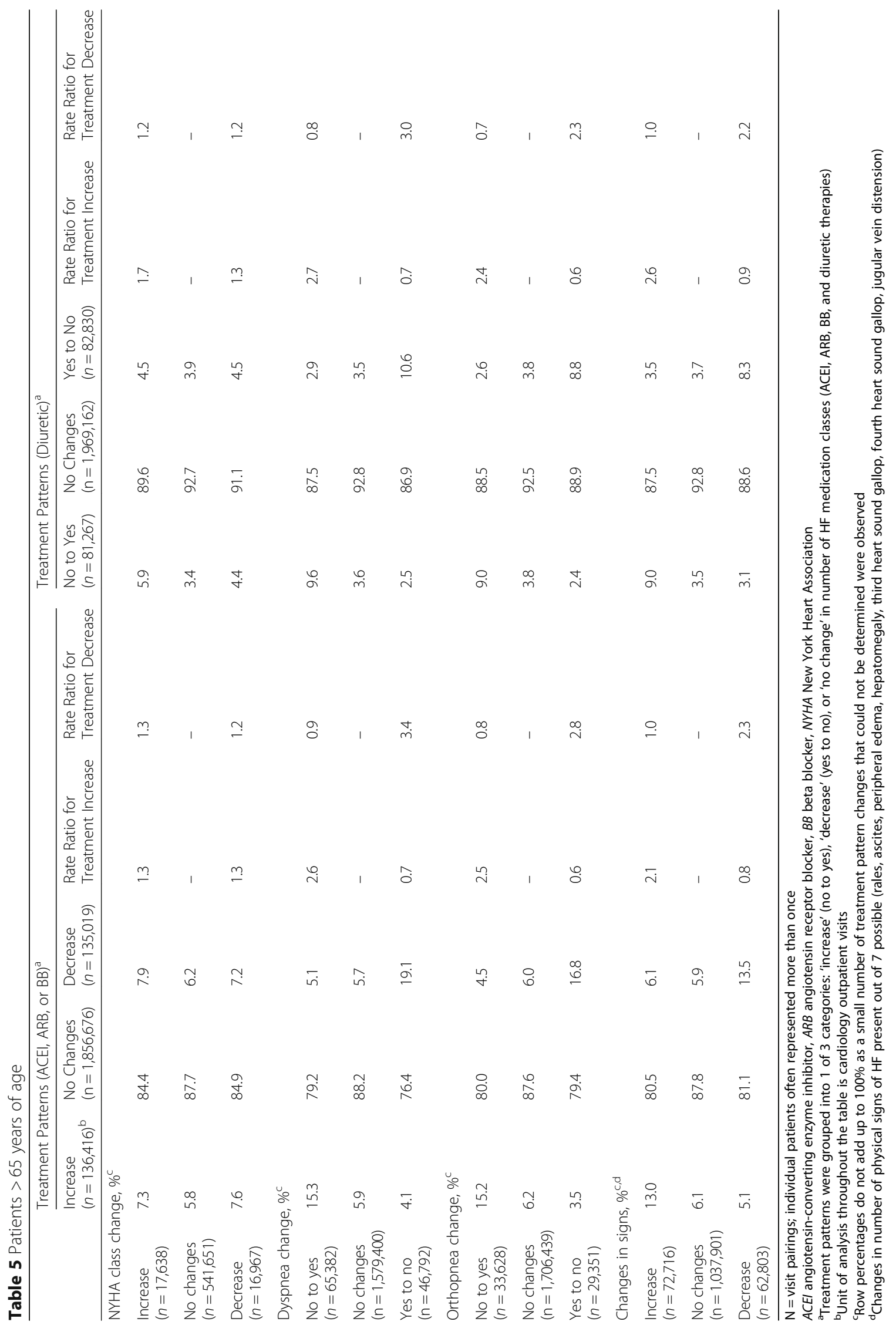


HF, and atrial fibrillation) from outpatient practices across the U.S. [19]. Here, the PINNACLE Registry has provided preliminary insights into what occurs at ambulatory cardiology visits for patients with HF.

Adherence to treatment guidelines has been shown to improve outcomes of patients with HF, including healthrelated quality of life. Poor health-related quality of life has been associated with many factors including greater symptom burden in patients with HF [7]. A patientcentered focus on symptom deterioration may facilitate more rapid and adequate care and reduce the need for hospitalizations $[8,25]$. In the current study, a lack of change in the index HF treatment was most often observed in the presence of worsening symptoms and signs. Previous studies have reported various rationales for not modifying treatment patterns in accordance with $\mathrm{HF}$ treatment guidelines, including medical reasons (e.g., tolerability) and human reasons (e.g., clinical inertia, patient preferences) [26]. Studies have also found lack of adherence to HF guidelines may more often be seen in older patients or those with comorbidities, due to concerns with clinical complexity of treatment and limited potential benefits for these patients [27]. Because of the nature of PINNACLE data, we are unable to comment on the reasons here, other than to say that these patterns were seen across LVEF and age groups. Future research could examine the association of dosage regimen optimization with symptom control to inform clinical practice.

A number of limitations with regard to the current study should be considered. Because indications for BB, ACEI, ARB, aldosterone antagonists, and newer agents are all dependent on LVEF, the lack of LVEF data in nearly half of patients limits the analysis. Fortunately, with the large sample size in PINNACLE, we were able to look at the subgroup of patients with HF with reduced LVEF and found that medication changes in this group were similarly low. The loss of detailed medication information when data were transformed for analysis (i.e., type of diuretic and dosage information) significantly limited the ability to understand the scope of therapy adjustments occurring at clinic visits $[18,28,29]$. For example, a patient could have her furosemide dose increased and spironolactone added, but these medication changes would still be classified by PINNACLE as "unchanged" diuretic. PINNACLE data capture does not allow for an analysis of HF medication dosing. Continuous advances in the interface and processing of electronic health records within PINNACLE are ongoing and should improve medication data capture in the future. Finally, outpatient cardiology practices voluntarily participating in the PINNACLE Registry may not optimally represent practice patterns across the U.S.; however, the characteristics of practices and patients in PINNACLE have been shown to mirror the broader U.S. cardiology ambulatory population.

\section{Conclusions}

Serial ambulatory HF visits in U.S. cardiology practices were common and rarely involved changes in symptoms and signs. HF medications were seldom added or removed at a class level. These findings may suggest opportunities for more proactive medication class optimization or, alternatively, for more symptom-based visit scheduling.

\begin{abstract}
Abbreviations
ACEl: Angiotensin-converting enzyme inhibitors; ARB: Angiotensin receptor blockers; BB: Beta blockers; CV: Cardiovascular; HF: Heart failure;

LVEF: Reduced left-ventricular ejection fraction; NCDR: National cardiovascular data registry; NYHA: New York heart association; PINNACLE: Practice innovation and clinical excellence; $S_{3}$ gallop: Third heart sound; $S_{4}$ gallop: Fourth heart sound
\end{abstract}

\section{Acknowledgments}

Write All Inc. (Sonoma, CA) provided medical writing and editorial assistance for this manuscript.

\section{Funding}

Funding for this study was provided by Novartis Pharmaceuticals Corporation and a NIH grant K23HL105896. The PINNACLE Registry is an initiative of the American College of Cardiology.

\section{Availability of data and materials}

The datasets generated and/or analyzed during the current study are available at the PINNACLE registry, https://cvquality.acc.org/NCDR-Home/ data-collection/pinnacle-data-collection.

\section{Authors' contributions}

$L A, F T, P J, T B, A P$, and ST have met the criteria for authorship set forth by the International Committee for Medical Journal Editors (ICMJE), and have contributed equally to the following: 1) conception and study design, or analysis and interpretation of data, or both; 2) design or analysis and interpretation of data, or both; 3) drafting of the manuscript or revising it critically for important intellectual content; and 4) final approval of the manuscript submitted. This article has not been published or accepted for publication in any other venue and is not under consideration at any other journal. The concepts have been presented as a poster consideration at the American Heart Association (AHA) Annual Meeting in New Orleans, LA; November 14, 2016.

\section{Ethics approval and consent to participate}

This study did not require informed consent or institutional review board approval because all data were accessed using techniques compliant with the Health Insurance Portability and Accountability Act of 1996. Thus, no identifiable protected health information was extracted during the course of the study period.

\section{Competing interests}

L.A. Allen has received research grants from the $\mathrm{NIH/NHLBI}, \mathrm{PCORI}$, and AHA as well as consultant/advisory board fees from Janssen and Novartis Pharmaceuticals Corporation. For this manuscript, LA's time was partially supported by NIH grant K23HL105896. S.J. Turner is an employee of Novartis Pharmaceuticals Corporation. F. Tang, P. Jones, T. Breeding, and A. Ponirakis declare no conflict of interest.

\section{Publisher's Note}

Springer Nature remains neutral with regard to jurisdictional claims in published maps and institutional affiliations.

\section{Author details}

'Division of Cardiology, University of Colorado School of Medicine, Anschutz Medical Campus, 12631 E. 17th Avenue, Academic Office 1, \#7019, Mail Stop B130, Aurora, CO 80045, USA. ${ }^{2}$ Saint Luke's Mid America Heart Institute, 4401 Wornall Road, Kansas City, MO 64111, USA. ${ }^{3}$ American College of Cardiology, Heart House, 2400 N Street NW, Washington, DC 20037, USA. ${ }^{4}$ Health Economics \& Outcomes Research, Novartis Pharmaceuticals Corporation, One Health Plaza 125/3410B, East Hanover, NJ 07936-1080, USA. 
Received: 12 October 2017 Accepted: 20 April 2018

Published online: 03 May 2018

\section{References}

1. Centers for Disease Control and Prevention. Heart Disease. http://www.cdc. gov/nchs/fastats/heart-disease.htm. Accessed 15 Mar 2017.

2. Storrow AB, Jenkins CA, Self WH, Alexander PT, Barrett TW, Han JH, et al. The burden of acute heart failure on U.S. emergency departments. JACC Heart Fail. 2014;2(3):269-77.

3. Mosalpuria K, Agarwal SK, Yaemsiri S, Pierre-Louis B, Saba S, Alvarez R, et al. Outpatient management of heart failure in the United States, 2006-2008. Tex Heart Inst J. 2014;41(3):253-61.

4. Mozaffarian D, Benjamin EJ, Go AS, Arnett DK, Blaha MJ, Cushman M, et al. Heart disease and stroke statistics-2016 update: a report from the American Heart Association. Circulation. 2016;133(4):e38-360.

5. Ekman I, Cleland JG, Swedberg K, Charlesworth A, Metra M, Poole-Wilson PA. Symptoms in patients with heart failure are prognostic predictors: insights from COMET. J Card Fail. 2005;11(4):288-92.

6. Beck da Silva L, Mielniczuk L, Laberge M, Anselm A, Fraser M, Williams K, et al. Persistent orthopnea and the prognosis of patients in the heart failure clinic. Congest Heart Fail. 2004;10(4):177-80.

7. Yancy CW, Jessup M, Bozkurt B, Butler J, Casey DE Jr, Drazner MH, et al. 2013 ACCF/AHA guideline for the management of heart failure: a report of the American College of Cardiology Foundation/American Heart Association task force on practice guidelines. Circulation. 2013; 128(16):e240-e327.

8. Yancy CW, Jessup M, Bozkurt B, Butler J, Casey DE Jr, Colvin MM, et al. 2016 ACC/AHA/HFSA focused update on new pharmacological therapy for heart failure: an update of the 2013 ACCF/AHA guideline for the management of heart failure: a report of the American College of Cardiology/American Heart Association task force on clinical practice guidelines and the Heart Failure Society of America. J Am Coll Cardiol. 2016;68(13):1476-88.

9. Bekelman DB, Rumsfeld JS, Havranek EP, Yamashita TE, Hutt E, Gottlieb SH, et al. Symptom burden, depression, and spiritual well-being: a comparison of heart failure and advanced cancer patients. J Gen Intern Med. 2009:24:592-8.

10. Fang J, Mensah GA, Croft JB, Keenan NL. Heart failure-related hospitalization in the U.S., 1979 to 2004. J Am Coll Cardiol. 2008:52:428-34.

11. Fonarow GC, Abraham WT, Albert NM, Stough WG, Gheorghiade M, Greenberg BH, et al. Factors identified as precipitating hospital admissions for heart failure and clinical outcomes: findings from OPTIMIZE-HF. Arch Intern Med. 2008;168:847-54

12. Fonarow GC, Yancy CW, Albert NM, Curtis AB, Stough WG, Gheorghiade M, et al. Improving the use of evidence-based heart failure therapies in the outpatient setting: the IMPROVE HF performance improvement registry. Am Heart J. 2007;154:12-38.

13. Allen LA, Fonarow GC, Liang L, Schulte PJ, Masoudi FA, Rumsfeld JS, et al. Medication initiation burden required to comply with heart failure guideline recommendations and hospital quality measures. Circulation. 2015;132:1347-53.

14. Kapoor JR, Kapoor R, Ju C, Heidenreich PA, Eapen ZJ, Hernandez AF, et al. Precipitating clinical factors, heart failure characterization, and outcomes in patients hospitalized with heart failure with reduced, borderline, and preserved ejection fraction. JACC Heart Fail. 2016;4:464-72.

15. Virani SS, Maddox TM, Chan PS, Tang F, Akeroyd JM, Risch SA, et al. Provider type and quality of outpatient cardiovascular disease care:insights from the NCDR PINNACLE Registry. J Am Coll Cardiol. 2015;66:1803-12.

16. Hira RS, Kennedy K, Nambi V, Jneid H, Alam M, Basra SS, et al. Frequency and practice-level variation in inappropriate aspirin use for the primary prevention of cardiovascular disease: insights from the National Cardiovascular Disease Registry's Practice Innovation and Clinical Excellence registry. J Am Coll Cardiol. 2015;65:111-21.

17. Chan PS, Maddox TM, Tang F, Spinler S, Spertus JA. Practice-level variation in warfarin use among outpatients with atrial fibrillation (from the NCDR PINNACLE program). Am J Cardiol. 2011;108:1136-40.

18. Chan PS, Oetgen WJ, Buchanan D, Mitchell K, Fiocchi FF, Tang F, et al. Cardiac performance measure compliance in outpatients: the American College of Cardiology and National Cardiovascular Data Registry's PINNACLE (practice innovation and clinical excellence) program. J Am Coll Cardiol. 2010;56(1):8-14.

19. American College of Cardiology. Outpatient Registries. http://cvquality.acc. org/NCDR-Home/Registries.aspx.
20. American College of Cardiology. NCDR ${ }^{\circledast}$ Outpatient Registries v1.4. Data Dictionary - Full Specifications for PINNACLE registry. https://cvquality.acc. org/docs/default-source/ncdr/Data-Collection/ pinnv1datadictionaryfullspecifications14.pdf?sfvrsn $=0$.

21. Radford MJ, Arnold JM, Bennett SJ, Cinquegrani MP, Cleland JG, Havranek $E P$, et al. ACC/AHA key data elements and definitions for measuring the clinical management and outcomes of patients with chronic heart failure: a report of the American College of Cardiology/American Heart Association task force on clinical data standards (writing committee to develop heart failure clinical data standards): developed in collaboration with the American College of Chest Physicians and the International Society for Heart and Lung Transplantation: endorsed by the Heart Failure Society of America. Circulation. 2005;112:1888-916.

22. Lee DS, Stukel TA, Austin PC, Alter DA, Schull MJ, You JJ, et al. Improved outcomes with early collaborative care of ambulatory heart failure patients discharged from the emergency department. Circulation. 2010;122:1806-14.

23. Booth CM, Tannock IF. Randomised controlled trials and population-based observational research: partners in the evolution of medical evidence. $\mathrm{Br} \mathrm{J}$ Cancer. 2014;110:551-5.

24. Fonarow GC. Improving quality of care and outcomes for heart failure - role of registries. Circ J. 2011;75:1783-90.

25. Shafazand M, Patel H, Ekman I, Swedberg K, Schaufelberger M. Patients with worsening chronic heart failure who present to a hospital emergency department require hospital care. BMC Research Notes. 2012;5:132.

26. Steinman MA, Dimaano L, Peterson CA, Heidenreich PA, Knight SJ, Fung KZ, et al. Reasons for not prescribing guideline-recommended medications to adults with heart failure. Med Care. 2013;51:901-7.

27. Steinman MA, Sudore RL, Peterson CA, Harlow JB, Fried TR. Influence of patient age and comorbid burden on clinician attitudes toward heart failure guidelines. Am J Geriatr Pharmacother. 2012;10:211-8.

28. Pokharel Y, Wei J, Hira RS, Kalra A, Shore S, Kerkar PG, et al. Guidelinedirected medication use in patients with heart failure with reduced ejection fraction in India: American College of Cardiology's PINNACLE India quality improvement program. Clin Cardiol. 2016;39:145-9.

29. Kalra A, Pokharel Y, Glusenkamp N, Wei J, Kerkar PG, Oetgen WJ, et al. Gender disparities in cardiovascular care access and delivery in India: insights from the American College of Cardiology's PINNACLE India quality improvement program (PIQIP). Int J Cardiol. 2016;215:248-51.

\section{Ready to submit your research? Choose BMC and benefit from:}

- fast, convenient online submission

- thorough peer review by experienced researchers in your field

- rapid publication on acceptance

- support for research data, including large and complex data types

- gold Open Access which fosters wider collaboration and increased citations

- maximum visibility for your research: over $100 \mathrm{M}$ website views per year

At BMC, research is always in progress.

Learn more biomedcentral.com/submissions 